\title{
A Study On Retrieval Practice And Immediate Memory
}

\author{
Dr. Piyali Roy \\ Assistant Professor, Department of Education, Bodoland University
}

\begin{abstract}
Memory is considered as a psychological process which is responsible for reproducing the events of past. Learning is impossible without the ability of memorization. It is common to all though there is an individual-difference regarding the range of remembering something. Immediate Memory is very helpful for students as it allows them to test their knowledge just after learning. At present the examination-oriented system of education requires a very strong range of memory for getting higher scores. In the present study, the investigator has tried to establish a connection between immediate memory and the students with and without the habit of retrieval practice. Review of related literature states a positive relation between retrieval practice and higher academic achievement. Again, academic achievement also requires the ability of memorization. In the present study, the investigator collected data from the university students regarding their study habits (presence or absence of self-testing) and categorized students in two different groups i.e. students with retrieval practice (A) and students without retrieval practice (B). The basic purpose of the study is to find out whether self-testing has any connection with immediate memory or not. If yes, then what are the levels of immediate memory of the students in Group A and B
\end{abstract}

Keywords

Immediate memory, retrieval practice, university students, learning

Article Received: 10 August 2020, Revised: 25 October 2020, Accepted: 18 November 2020

\section{Introduction}

Modern education system is basically examination-centred. Every student must experience some examination in order to receive higher education where they have to show some skill learnt previously. It means memory occupies a significant place in our modern-formal system of education. Memory is described as the revival process that helps to re-establish the past experiences in its original form as far as possible. It is nothing but remembering what has been learnt already in a past event. Among the various types of memory like, habit memory, true memory, immediate memory, permanent memory, sensory memory etc. our present study is concerned with 'immediate memory' of the students. It refers to the capacity of a person to remember a certain amount of information for a small period of time. This is very much influenced by the method of repetition i.e. more we practice, more we remember. In the same way, just after reading something when a student goes through self-testing that brings an everlasting effect in his/her memory.

Retrieval practice is a basically known as a strategy in which bringing information to mind enhances learning. It makes learning effortful, meaningful and challenging. Because retrieving information demands complete mental effort. We sometime think we are performing poorly if we can't recall or remember something. We may feel like progress is slow. But, we should understand that the more difficult the retrieval practice, the better it is for retaining the learning for long-term. Struggling to learn through selftesting is much more effective than re-reading, taking and making notes, listening to lectures etc. Slower, effortful retrieval leads to long-term learning. Retrieval practice or self-testing is very much important to develop the power of memory. It also helps to achieve higher scores in the examinations. It is very important for the students to realize the mnemonic advantages of self-testing method. Students repeatedly study their books but hardly go for the revival practice i.e. to check the information which is already known to them, which is very helpful in learning (Karpicke, Butler and Roediger). A quick retrieval practice is a very useful tool to store information permanently by giving focus on perceiving, remembering and reasoning (Lutz and Huitt). There is individual difference regarding the ability of memorization. The load or pressure of information and the excessive number of objects may also cause short-term memory to some individuals (Alvarez and Cavanagh). So, to remember things properly retrieval system is an impeccable instrument or method. It has been also found that a robust detailed learning helps in the immediate reproduction of tasks (KARPICKE and PISONI). Therefore, a close relationship can be established between immediate memory and retrieval practice. Generally, psychologists and educationists connect retrieval practice with long-term memory. But, in this paper focus has been given to find out whether people who practice self-testing regularly can remember something immediately after learning or not. It has also been observed that no such study regarding the effect of retrieval practice on immediate memory is conducted in Kokrajhar District before. So, the investigator has conducted the present study to develop some clear ideas in this field.

\section{Objective Of The Study}

The objectives of the present study are stated below:

2.1 To find out the different levels of the students with and without retrieval practice.

2.2 To identify the students with and without retrieval practice on the basis of gender.

\section{Delimitation Of The Study}

The delimitations of the study are mentioned below-

1. The present study is confined to a sample of 500 post-graduate students only. 
2. The study is limited to the students of Bodoland Territorial Region (Assam, India) only.

3. The study includes the students of PG section covering the academic session of 2018-2020.

\section{Methodology}

\section{Sample}

In the present study the investigator selected the sample of 500 university students (250 in each Group A and B) from BTR Assam (India) irrespective of their courses of study, gender (male/female), locality (urban/rural) and management type of college (private/government) by applying Convenient Sampling Technique.

tools:

For conducting the present study the investigator had used the following tools-

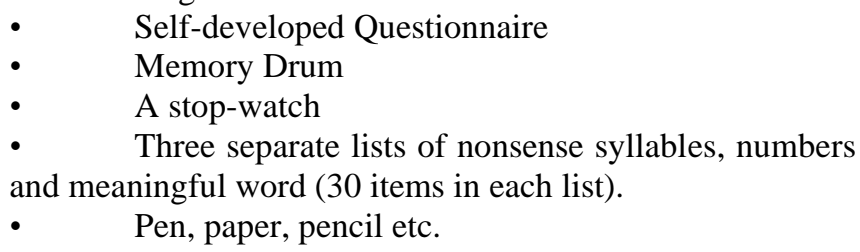

\section{Description of the apparatus and procedure of conducting the test:}

'Memory Drum' is a very demanding and standard American apparatus used in the field of memory research. Hermann Ebbinghaus published "Memory: A contribution to Experimental Psychology" in 1885 which influenced two famous psychologists Georg Elias Mueller and Friedrich Schumann to a great extent and as a result in 1887 we found the Memory Drum. The apparatus is still going through different experiments and innovations and it is also used differently by different researchers. For the present study the investigator has used a box-shaped apparatus. The box is closed with a small door and has sufficient space inside. There is a knob-stick inside the box which is placed horizontally and can be moved by pressing the knob from outside. Three separate lists of 30 nonsense syllables (4 alphabets), 30 numbers (each number is considered with 3 different digits) and 30 meaningful words are also prepared. The investigator placed those lists on the knob-stick one after another by opening the door of the Memory Drum. The subject can see the lists through some small windows which are again closed with five small metal screens.

At first, the list having 30 nonsense syllables were pasted on the knob-stick. Three seconds were given against each nonsense syllable and the knob-stick was moved after that. In this way the entire list was shown to the subject and the whole procedure took 90 seconds $(3 \times 30)$. The second list contained 30 numbers and in the third list 30 meaningful words were given to remember. 30 seconds were given to show these lists. After showing each list, the subject was given a plain paper and pencil to reproduce the nonsense syllables, numbers and meaningful words correctly. There was no time limitation to give responses. After writing the responses the subject returned the response sheets to the investigator for further analysis.

\section{Collection of Data:}

The investigator has collected data from the college students through different phases, like-

i. At first, the investigator distributed a selfdeveloped questionnaire to 789 university students in BTR area. It was simply designed to collect different information, opinions and views of the students regarding retrieval practice and also to identify the students who are involved in retrieval practice or self-testing after reading and those who do not. Then among them only 500 students were selected for conducting the present study by dividing them into two equal groups- Group A (250 students), who are engaged in retrieval practice and Group B (250 students), who do not apply retrieval practice. These groups were selected for further data collection.

ii. In the second phase, the investigator used memory drum and showed all the three lists to each sample separately in a psychological laboratory. The students gave responses after observing the lists properly and the responses were recorded by the investigator.

\section{Analysis And Interpretation Of Data}

After collecting data, it was analyzed and interpreted properly on the basis of the objectives of the study. At first, attempt is made to identify the different levels of immediate memory in connection to retrieval practice. Again, the study has also tried to identify the students who practice selftesting or not on the basis of their gender.

\section{Levels of the students with and without retrieval practice:}

The investigator categorized the 500 students into four levels separately on the basis of their correct responses, viz. Very Good (correct responses above 75\%), Good (correct responses from $51 \%$ to $75 \%$ ), Average (correct responses from $26 \%$ to $50 \%$ ) and Poor (correct responses $25 \%$ or below that). Scores are separately computed for each group and the number of students in each level of two groups can be shown through the following table-

Table 1: Levels of Immediate Memory

\begin{tabular}{|c|c|c|c|c|}
\hline \multirow{2}{*}{ GROUPS } & \multicolumn{4}{|c|}{ Levels of Immediate Memory } \\
\cline { 2 - 5 } & Very good & Good & Average & Poor \\
\hline $\begin{array}{c}\text { A } \\
(250 \text { students })\end{array}$ & $155(62 \%)$ & $55(22 \%)$ & $30(12 \%)$ & $10(4 \%)$ \\
\hline $\begin{array}{c}\text { B } \\
(250 \text { students })\end{array}$ & $33(13 \%)$ & $45(18 \%)$ & $67(27 \%)$ & $105(42 \%)$ \\
\hline
\end{tabular}

The above mentioned table shows that students with retrieval practice scored very high $(62 \%)$ in remembering something immediately after learning. 22\% scored as 'good', 12\% were found 'average' and only 4\% students were found having poor performance in remembering 
something. But, students who do not have any connection with retrieval practice, their results show a completely different outcome than the other group. Here, majority of the students $(42 \%)$ fall in poor category in remembering something immediately. Again, 27\% fall under 'average', $18 \%$ fall under 'good' and 13\% fall under 'very good' categories respectively. Different levels or categories of immediate memory and the percentage of individuals in Group A (retrieval practice) and Group B (absence of retrieval practice) can be compared through the following graphical representation-

Fig. 1: Categorization of the Students with and without Retrieval Practice

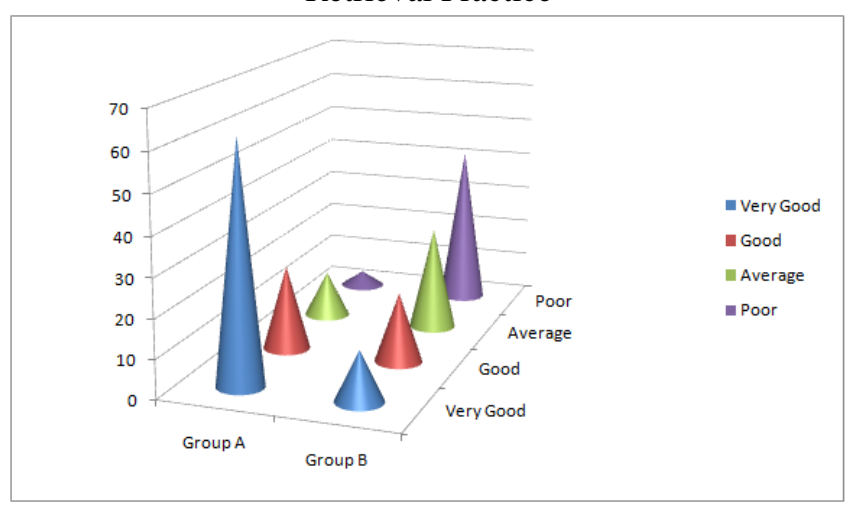

Identifying the students with and without retrieval practice on the basis of gender:

The study also tries to identify the male and female students separately who practice self-learning or not. In group A and B both boys and girls participated spontaneously. They performed their tasks and helped in gaining a positive outcome of the study. The following table shows students with and without retrieval practice on the basis of gender-

Table No. 2: Retrieval practice on the basis of gender

\begin{tabular}{|c|c|c|c|}
\hline & Male & Female & Total \\
\hline Group A & $83(33.2 \%)$ & $167(66.8 \%)$ & 250 \\
\hline Group B & $129(51.6 \%)$ & $121(48.4 \%)$ & 250 \\
\hline
\end{tabular}

In the table it is found that girls are indulged more in selftesting $(66.8 \%)$ than the boys $(33.2 \%)$. Again, in case of Group B i.e. students without retrieval practice the number of boys are higher $(51.6 \%)$ than the girls $(48.4 \%)$. This can also be shown with the following graphical representation-

Fig. 2: Students with and without retrieval practice on the basis of gender

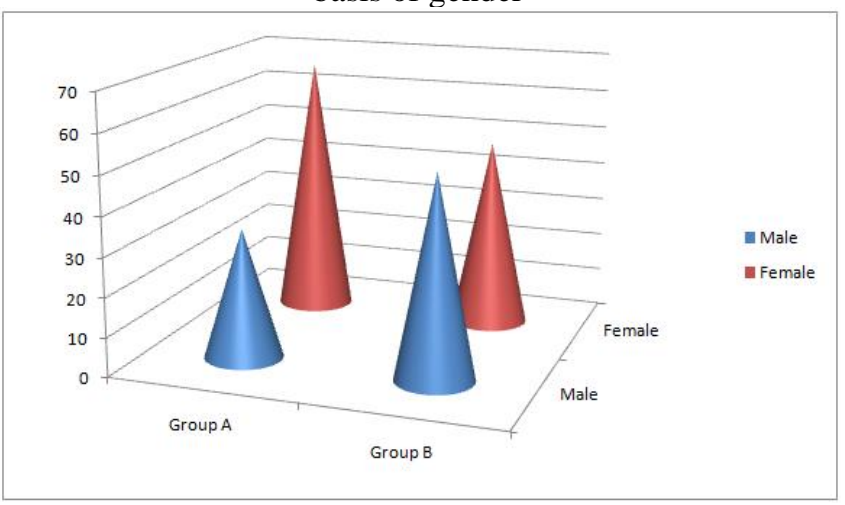

\section{Findings And Conclusion}

The finding of the study clearly shows that retrieval practice has an influence on immediate memory. Students who practiced self-testing scored higher than those who do not practice it. The scores of Group A are much higher than Group B in first two categories i.e. Very Good and Good. But, Group B scored higher in the other two categories viz. Average and Poor. It has been also found that female students are more involved in self-testing than their male counterparts. Hence, every educational expert should motivate and inspire their students for retrieval practice to achieve higher scores as evaluation today is examinationoriented mostly. It may also help in reducing errors in learning something and in achieving perfection in the concerned activity. Thus, we may conclude that retrieval is nothing but a learning event. Practicing retrieval or selftesting is a simple and effective way to enhance immediate and meaningful learning. For students we can say selftesting is a very good idea for knowledge check. But, they should not stop only after getting a successful retrieval; two or three additional spaced retrievals will boost in learning something immediately

\section{References}

[1] Karpicke, Butler and Roediger (2009), Page No. 471-479, Memory, Psychology Press Taylor and Francis Group.

[2] Lutz and Huitt (2003), Page no. 1-17, Educational Psychology Interactive. Valdosta, GA: Valdosta State University.

[3] Alvarez and Cavanagh (2004), page no. 106-111, Volume 15, American Psychological Society.

[4] KARPICKE and PISONI (2004), page no. 956-964, Memory \& Cognition, 32 (6), 956-964.

[5] Cavanagh (1972), Psychological Review, vol. 79, No. 6, page no. 525-530.

[6] Agarwal, P.K., Karpicke, J. D., Kang, S.H.K., Roediger, H.L., \& McDermott, K.B. (2008). Examining the testing effect with open- and closed-book tests. Applied Cognitive Psychology, 22(7), 861-876. doi:10.1002/acp.1391.

[7] Balota, D.A., Duchek, J.M., SergentMarshall, S.D., \& Roediger, H.L. (2006). Does expanded retrieval produce benefits over equal-interval spacing? Explorations of spacing effects in healthy aging and early stage Alzheimer's disease. 
Psychology and Aging, 21(1), 19-31. doi:10.1037/0882-7974.21.1.19.

[8] Blunt, J.R., \& Karpicke, J.D. (2014). Learning with retrieval-based concept mapping. Journal of Educational Psychology, 106(3), 849-858. doi:10.1037/a0035934.

[9] Butler, A.C. (2010). Repeated testing produces superior transfer of learning relative to repeated studying. Journal of Experimental Psychology: Learning, Memory, and Cognition, 36(5), 11181133. doi:10.1037/a0019902, 10.1037/a0019902.supp.

[10] Callender, A.A., \& McDaniel, M.A. (2009). The limited benefits of rereading educational texts. Contemporary Educational Psychology, 34(1), 30-41. doi:10.1016/j.cedpsych.2008.07.001.

[11] Chan, J.C.K. (2009). When does retrieval induce forgetting and when does it induce facilitation? Implications for retrieval inhibition, testing effect, and text processing. Journal of Memory and Language, 61(2), 153-170. doi:10.1016/j.jml.2009.04.004.

[12] Grimaldi, P.J., \& Karpicke, J.D. (2014). Guided retrieval practice of educational materials using automated scoring. Journal of Educational Psychology, 106(1), 58-68. doi:10.1037/a0033208.

[13] Hinze, S.R., \& Wiley, J. (2011). Testing the limits of testing effects using completion tests. Memory, 19(3), 290-304. doi:10.1080/09658211.2011.560121.

[14] Karpicke, J.D. (2009). Metacognitive control and strategy selection: Deciding to practice retrieval during learning. Journal of Experimental Psychology: General, 138(4), 469-486. doi:10.1037/a0017341.

[15] Karpicke, J.D., \& Bauernschmidt, A. (2011). Spaced retrieval: Absolute spacing enhances learning regardless of relative spacing. Journal of Experimental Psychology: Learning, Memory, and Cognition, 37(5), 1250-1257. doi:10.1037/a0023436.
[16] Karpicke, J.D., \& Blunt, J.R. (2011). Retrieval practice produces more learning than elaborative studying with concept mapping. Science, 331(6018), 772-775. doi:10.1126/science.1199327.

[17] Karpicke, J.D., Butler, A.C., \& Roediger, H.L. (2009). Metacognitive strategies in student learning: Do students practise retrieval when they study on their own? Memory, 17(4), 471-479. doi:10.1080/09658210802647009.

[18] Karpicke, J.D., \& Roediger, H.L. (2008). The critical importance of retrieval for learning. Science, 319(5865), 966-968. doi:10.1126/science.1152408.

[19] Larsen, D.P., Butler, A.C., Lawson, A.L., \& Roediger, H.L., III. (2013). The importance of seeing the patient: Testenhanced learning with standardized patients and written tests improves clinical application of knowledge. Advances in Health Sciences Education, 18(3), 409425. doi:10.1007/s10459-012-9379-7.

[20] Lindsey, R.V., Shroyer, J.D., Pashler, H., \& Mozer, M.C. (2014). Improving students' long-term knowledge retention through personalized review. Psychological Science, 25(3), 639-647. doi:10.1177/0956797613504302.

[21] https://www.retrievalpractice.org/why-itworks 